\title{
Saudi Arabia Guidelines for diabetic macular edema
}

\author{
A consensus of the Saudi Retina Group
}

Abdullah S. AlQahtani, MD, DES, Mohammad A. Hazzazi, BsC, MD, Saad A. Waheeb, MD, FRCSC, Valmore A. Semidey, MD, Hussein K. Elgendy MD, FRCS, Wajeeha I. Alkhars, MD, FRCS, Marwan A. Abouammoh, MD, Hassan Al-Dhibi, MD.

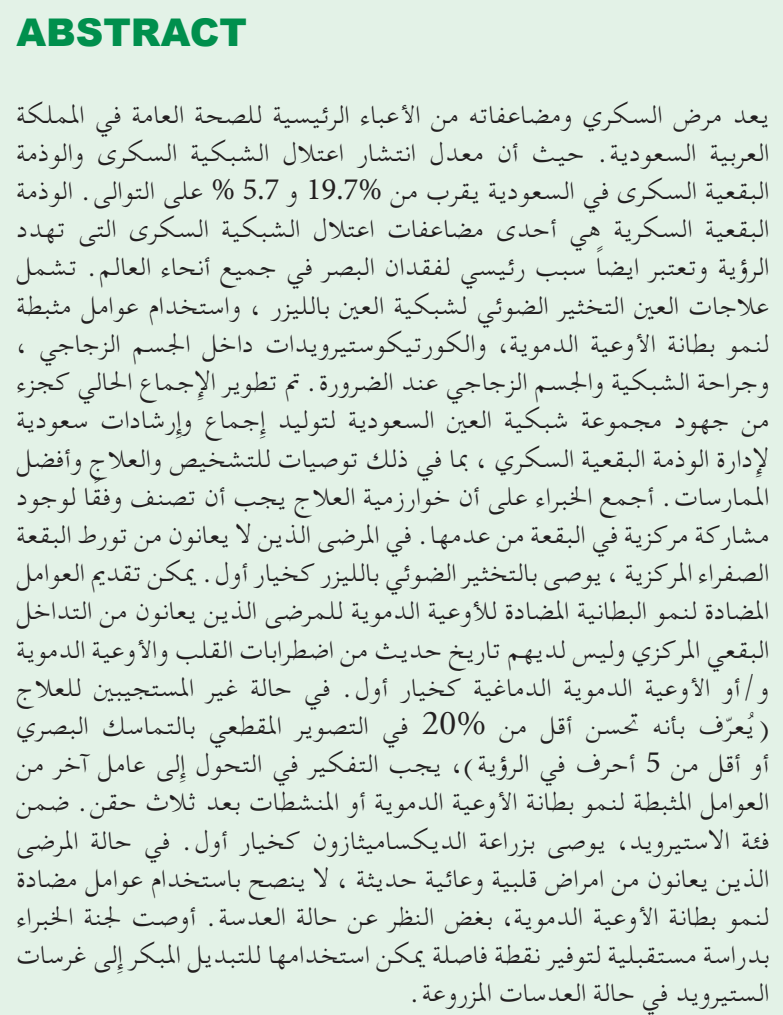

Diabetes mellitus (DM) and its complications are major public health burdens in Saudi Arabia. The prevalence of diabetic retinopathy (DR) is $19.7 \%$ and the prevalence of diabetic macular edema (DME) is $5.7 \%$ in Saudi Arabia. Diabetic macular edema is a vision-threatening complication of DR and a major cause of vision loss worldwide. Ocular treatments include retinal laser photocoagulation, anti-vascular endothelial growth factor (anti-VEGF) agents, intravitreal corticosteroids, and vitreoretinal surgery when necessary. The present consensus was developed as a part of the Saudi Retina Group's efforts to generate Saudi guidelines and consensus for the management of DME, including recommendations for its diagnosis, treatment, and best practice. The experts' panel stipulates that the treatment algorithm should be categorized according to the presence of central macula involvement. In patients with no central macular involvement, laser photocoagulation is recommended as the first-line option. Patients with central macular involvement and no recent history of cardiovascular (CVS) or cerebrovascular disorders can be offered anti-VEGF agents as the firstline option. In the case of non-responders (defined as an improvement of $<20 \%$ in optical coherence tomography or a gain of fewer than 5 letters in vision), switching to another anti-VEGF agent or steroids should be considered after 3 injections. Within the class of steroids, dexamethasone implants are recommended as the first choice. In patients with a recent history of CVS events, the use of anti-VEGF agents is not recommended, regardless of their lens status. The experts' panel recommends that a future study be conducted to provide a cut-off point for early switching to steroid implants in pseudo-phakic eyes.

Keywords: diabetic macular edema, consensus, Saudi arabia, diabetic retinopathy, laser

Saudi Med J 2021; Vol. 42 (2): 131-145

doi: 10.15537/smj.2021.2.25623

From the Department of Surgery (AlQahtani), Division of Ophthalmology, National Guard Hospital, and from King Saud bin Abdulaziz University for Health Sciences; from the Department of Ophthalmology (Waheeb), King Fisal Specialist Hospital and Research Center; from the Department of Ophthalmology (Elgendy), Retina Unit, Magrabi Eye and Ear Hospital, Jeddah; from the Department of Surgery (Hazzazi), Division of Ophthalmology, Riyadh National Guard Hospital, and from King Saud bin Abdulaziz University for Health Sciences; from the Department of Vitreoretinal (Semidey, AlDhibi), King Khalid Eye Specialist Hospital; from the Department of Ophthalmology (Abouammoh), College of Medicine, King Saud University, Riyadh; and from the Department of Retina and Uveitis (Alkhars), Dhahran Eye Specialist Hospital, Dhahran, Kingdom of Saudi Arabia.

Received 15th September 2020. Accepted 8th December 2020.

Address correspondence and reprint request to: Dr. Hassan Al-Dhibi, Vitreoretinal \& Uveitis Senior Academic Consultant, Chief Uveitis Division, King Khalid Eye Specialist Hospital, Riyadh, Kingdom of Saudi Arabia. E-mail: Hdhibi@gmail.com

ORCID ID: https://orcid.org/0000-0002-0621-1234 
$\mathrm{D}$ iabetes mellitus (DM) poses a major global public health burden and has significant morbidity and mortality. ${ }^{1}$ Recent global figures have estimated that one in every 11 adults has DM (90\% type 2 diabetes), while DM accounted for 1.6 million deaths in 2016 globally.,3 In patients with long-term DM or uncontrolled hyperglycemia, a cascade of vascularrelated pathological changes leads to a wide range of microvascular and macrovascular complications, including accelerated atherosclerosis, cerebrovascular diseases, coronary artery diseases, diabetic nephropathy, diabetic neuropathy, and diabetic retinopathy (DR). ${ }^{4-6}$ Diabetic macular edema (DME) is a vision-threatening complication of DR and a major cause of vision loss worldwide. ${ }^{7}$ The incidence of DME increases with increased diabetes duration, affecting almost $40 \%$ of diabetic patients within 30 years after the onset of disease. ${ }^{8}$ Moreover, patients with type 1 diabetes are at a higher risk of DME than those with type 2 diabetes. ${ }^{9}$ Other risk factors for DME include poorly controlled glycemic status, cardiovascular disease, deteriorated renal function, and use of diuretics. ${ }^{10}$ Though the exact pathogenesis of DME is not fully understood, different pathogenetic factors such as uncontrolled hyperglycemia, impaired lipid profile, and inflammatory

Disclosure. All authors declare that they have no proprietary interests in the products described in the article and received no financial support for the research, authorship, and/or publication of this article. The authors also declared the following potential conflicts of interest: Abdullah Alqahtani has sat on advisory boards for Allergan, Novartis, Bayer, and Alimera; and has received a speaker honorarium from Allergan, Novartis, Bayer, and Alimera. Saad A. Waheeb is the principal investigator for trials sponsored by Bayer, has sat on advisory boards for Allergan, Novartis, Bayer; and has received a speaker honorarium from Allergan, Novartis, and Bayer. Hassan Al-Dhibi has received a consultant and advisory board member honorarium from Allergan, Novartis, and Bayer. Mohammad A. Hazzazi has received a speaker honorarium from Allergan, Novartis, and Bayer. Valmore A. Semidey has attended advisory board meetings for Allergan. Hussein K. Elgendy has sat on advisory boards for Allergan, Novartis, and Bayer, and has received a speaker honorarium from Allergan, Novartis, and Bayer. Marwan A. Abouammoh and Wajeeha I. Alkhars declare no other conflicts of interest. The authors also declare that: All authors contributed equally in interpreting the results, editing, and approving the manuscript before submission. mediators have been implicated in the development of DME. ${ }^{11}$ Recently, a growing body of evidence has shown that retinal hypoxia contributes to the pathogenesis of DME. Hypoxia leads to an increased expression of vascular endothelial growth factor (VEGF), a potent inducer of vascular permeability, and leakage from retinal vessels. ${ }^{12,13}$

Various modalities are available for the diagnosis of DME. The presence of focal macular changes and exudates can be visualized by slit-lamp biomicroscopy of the posterior pole. Other diagnostic methods include fundus fluorescein angiography (FFA) for retinal capillary leakage/ischemia and optical coherence tomography (OCT) for cross-sectional imaging. ${ }^{14}$ Preventive strategies for DME include proper glycemic control, reduced blood lipid levels, and regulation of systemic blood pressure. ${ }^{14}$ Ocular treatments include retinal laser photocoagulation, anti-VEGF agents, intravitreal corticosteroids, and vitreoretinal surgery when necessary. ${ }^{15}$ Recently, micropulse laser is used instead of the traditional laser photocoagulation in DME patients. Ophthalmologists favor micropulse laser due to its better therapeutic effect and fewer side effects (such as visual field defects, epiretinal fibrosis, and choroidal neovascularization) compared to conventional photocoagulation. ${ }^{16,17}$

Pars plana vitrectomy (PPV) procedure is performed in DME cases when laser therapy and anti-VEGF failed to produce a desirable effect. ${ }^{15}$ Pars plana vitrectomy performed by the mechanical removal of vitreous humor; thus, reducing the thickness of the macula and improve visual acuity (VA).

Saudi Arabia is the largest country in the Arabian Peninsula, with a population of over 28 million. ${ }^{18}$ The prevalence of DR is $19.7 \%$ and the prevalence of DME in Saudi Arabia is 5.7\%. ${ }^{19}$ However, published data on the characteristics and treatment patterns of DME patients in Saudi Arabia are scarce.

This consensus meeting brought together a panel of experts in DME to share their views on current trends and practices in Saudi Arabia and how they compare with the global picture to develop local treatment guidelines for DME.

Consensus development. The present consensus was developed as a part of the Saudi Retina Group's efforts to generate local Saudi treatment guidelines and consensus for the management of DME and to obtain recommendations based on the best-updated practice. Eight consultant ophthalmologists participated in the consensus development and represented 7 Saudi specialized institutions: 6 from the government sector and one from the private sector. 
Definition and pathogenesis of DME. Diabetic macular edema is an accumulation of fluid in the macula part of the retina due to leakage of blood vessels. It involves the deterioration of the blood-retinal barrier in the eye and a resulting pooling of fluid within the retina's central area. This capillary leakage causes diffuse edema, whereas focal or multifocal leakage from grouped microaneurysms leads to localized edema. ${ }^{20}$

Most of the published literature adopts the criteria developed by the Early Treatment Diabetic Retinopathy Study (ETDRS) for the definition of clinically significant DME. The ETDRS defined clinically significant DME as the presence of retinal thickness/hard exudates within $500 \mu \mathrm{m}$ of the macular center or a retinal thickness of one disk diameter within one disk diameter of the macular center. ${ }^{11,21}$

The pathological hallmark of DME is the presence of increased vascular permeability, prompting the accumulation of intraretinal fluid, mainly in the inner and outer plexiform layers. However, the pathogenic mechanisms that lead to dysfunctions in the retinal barriers are not yet fully understood. Classical contributors to the development of DME include prolonged or uncontrolled hyperglycemia, impaired lipid profile, advanced glycation end-products, and protein kinase C. ${ }^{11}$ Over the past 3 decades, the role of hypoxia in the pathogenesis of DME has been elucidated by the accumulating evidence. Through its catecholaminergic effect, hypoxia induces the expression of VEGF and hypoxia-inducible factor- $1 \alpha$ via $\alpha$-adrenergic receptors, which in return stimulate the release of proangiogenic factors and formation of new vessels. ${ }^{22,23}$ Overexpression of VEGF is a common consequence of various pathological processes in DME. Increased levels of VEGF disturb the blood-retinal barrier through stimulation of adhesion molecules and neuronal apoptosis. ${ }^{24,25}$ Thus, the introduction of anti-VEGF agents has revolutionized the management of DME. ${ }^{26}$ Nevertheless, a considerable proportion of patients are resistant to anti-VEGF therapy, which highlights the significant involvement of other pathophysiological mechanisms of DME. ${ }^{27}$

Various inflammatory processes have emerged as significant contributors to the development of DME. Hyperglycemia induces overexpression of intercellular adhesion molecule (ICAM)-1 and monocyte chemotactic protein 1 (MCP-1) in vitreous fluid, leading to leukocyte adhesion. In return, leucocytes stimulate the release of cytokines and other mediators, leading to damage of the retinal barrier. ${ }^{28}$ According to Noma et $\mathrm{al}^{29}$ the levels of several inflammatory markers, VEGF receptor (VEGFR)-2, ICAM-1, MCP-1, and pentraxin 3 (PTX3), were higher in the vitreous of patients with DME. In addition, the aqueous flare value was significantly correlated with the vitreous fluid levels of these inflammatory findings. These findings highlight the role of the inflammatory process in the disruption of the blood-retinal barrier.

Consensus statement. Most experts agreed that the involvement of the central macula should be considered in any diagnosis of significant DME. The experts' panel reached a consensus that DR and DME pathogeneses are interconnected. They also agree that inflammation plays a role in recurrent DME.

Epidemiology of DME. According to the 2012 global meta-analysis by $\mathrm{Yu}$ et $\mathrm{al}^{30}$ the overall agestandardized prevalence of DME is $6.81 \%(6.74 \%$ to $6.89 \%$ ), with a higher prevalence in patients with type 1 DM than in those with type 2 DM $(12.3 \%$ versus $11.9 \%$ ). In a more recent review by Lee et al, ${ }^{31}$ the global prevalence of DME was $4.2 \%$ to $8 \%$ in type $1 \mathrm{DM}$ and 1.4 to $12.8 \%$ in type $2 \mathrm{DM}$. In addition, it was reported that DME leads to vision loss in more than 10,000 new cases annually. ${ }^{32}$ Recent figures show that the prevalence of DME in the United States (US) is $3.8 \% .{ }^{33} \mathrm{~A}$ similar prevalence was reported in Europe $(3.7 \%) .^{34}$

The prevalence of DME among patients with diabetes is generally much lower than that of DR. However, no observed geographical variations in the incidence of DME have been reported. ${ }^{35-38}$ In the Wisconsin Epidemiologic Study of Diabetic Retinopathy cohort, in which patients were followed up for 25 years, the incidence of DME increased proportionally with the duration of type 1 diabetes and plateaued after 14 years of follow-up (29\%). ${ }^{7}$

In the Middle East, the age-standardized prevalence of clinically significant DME was $4.9 \%$ in Iran, $4.2 \%$ in Tunisia, and $11.5 \%$ in Egypt. ${ }^{36,39,40}$ The situation appears to be similar in Saudi Arabia. In a large cross-sectional study, Al-Rubeaan et al $^{19}$ obtained the data of 50,464 type 2 diabetes patients from the Saudi National Diabetes Registry (SNDR) and found that the prevalence of DR was $19.7 \%$ and DME was $5.7 \%$. In another report of 3,052 patients from Taif, the prevalence of sight-threatening DR among diabetic patients was $17.5 \% .{ }^{41}$ In a random sample of 690 diabetic patients from Al-Madinah Al-Munawarah (the western region of Saudi Arabia), the prevalence of DR was $36.1 \%$, of which $6.4 \%$ was proliferative DR. ${ }^{42}$ In Southern Saudi Arabia, the prevalence of DR was $27.8 \%$ and maculopathy was $7.8 \% .^{43}$ The prevalence of DR in urban areas of Al-Hasa (an eastern region of 
KSA) was $30.5 \%$ and rural was $28.6 \% .{ }^{44}$ The prevalence of DR in Ha'il, KSA was reported to be $28.6 \% .{ }^{45}$

Consensus statement. Saudi Arabia is among the countries with the highest prevalence of DM and its complications, with regional variations. The incidence of DME ranges between 6\% and 10\% among Saudi patients with diabetes. Diabetic macular edema cases in Saudi Arabia are underreported, which may lead to the false notion of a lower incidence of DME in the Kingdom than in other parts of the world. Therefore, there is a need for a central unified and updated National Registry in order to reflect the current trends of DME patients in Saudi Arabia.

Diagnosis of DME. The initial evaluation of DME depends on the visualization of macular thickness, exudates, and cystoid changes using contact lens-aided slit-lamp biomicroscopy. ${ }^{14}$ Previous reports revealed that both slit-lamp biomicroscopy and stereo fundus photography are insensitive to mild and early changes in retinal thickness. ${ }^{46}$

Another important imaging technique in the evaluation of DME is FA. It is a qualitative method for the detection of active leakage. The angiogram visualizes both active leakage and capillary non-perfusion. Fluorescein angiography findings do not correlate with the clinical severity of retinal thickness or edema. ${ }^{47}$ Thus, FA is not indicated for the diagnosis of DME. However, it is usually performed when treatment is planned to assess treatable lesions by laser or to rule out macular/peripheral retinal ischemia. ${ }^{48}$

Optical coherence tomography provides highresolution imaging of the retina and quantitative assessment of changes in retinal thickness or edema. It can also demonstrate a number of microanatomical features in DME. Hard exudates are seen as small hyperreflective lesions typically found in the outer plexiform layer. Optical coherence tomography can also show intraretinal and subretinal fluid, seen as dark "spaces" in and under the retina, respectively. It can also demonstrate areas of subclinical macular edema as well as help to confirm the absence of macular thickening. In addition, OCT can demonstrate loss of different layers of the retina, such as the photoreceptors or nerve fiber layer, which can sometimes help to explain the visual loss in patients without other macular abnormalities. It is also useful in demonstrating abnormalities of the vitreoretinal interface, such as epiretinal membranes or vitreomacular traction, which may be more amenable to surgical therapy. ${ }^{49}$

In the setting of DME, OCT is indicated for the diagnosis of clinically significant edema, assessment of
Table 1 - Reported cut-off values according to different optical coherence tomography (OCT) machines.

\begin{tabular}{lccccc}
\hline Machine & $\begin{array}{c}\text { Bentaleb- } \\
\text { Machkour } \\
\text { et al }{ }^{54}\end{array}$ & $\begin{array}{c}\text { Cochrane } \\
\text { review }^{55}\end{array}$ & $\begin{array}{c}\text { Brown } \\
\text { et al }^{56}\end{array}$ & $\begin{array}{c}\text { Campbell } \\
\text { et a }^{57}\end{array}$ & $\begin{array}{c}\text { Goebel } \\
\text { et al }^{58}\end{array}$ \\
\hline Stratus OCT & $197 \mu \mathrm{m}$ & $230 \mu \mathrm{m}$ & $300 \mu \mathrm{m}$ & $240 \mu \mathrm{m}$ & NA \\
$\begin{array}{l}\text { Cirrus HD- } \\
\text { OCT }\end{array}$ & $254 \mu \mathrm{m}$ & $254 \mu \mathrm{m}$ & NA & NA & NA \\
$\begin{array}{l}\text { Spectralis } \\
\text { HRA+OCT }\end{array}$ & $236 \mu \mathrm{m}$ & $300 \mu \mathrm{m}$ & NA & NA & NA \\
$\begin{array}{l}\text { OCT 2000 } \\
\text { scanner }\end{array}$ & NA & NA & NA & NA & $230 \mu \mathrm{m}$ \\
\hline
\end{tabular}

OCT: optical coherence tomography, HRA: heidelberg retina angiograph

severity, plan for treatment, and follow-up for treatment results. ${ }^{50}$

Optical coherence tomography is a more tolerable modality than FA, as it depends on infrared illumination of the fundus without invasive measures. ${ }^{51}$ Recent reports have demonstrated the predictive utility of OCT in terms of the success rate of various therapies through its ability to detect changes in macular volume, retinal thickness, and the presence of hyperreflective foci. ${ }^{52}$ The disadvantages of currently available OCT machines include the fact that image quality can be affected by media opacities, and the reliability of the data is operator-dependent. ${ }^{53}$ There are 2 types of OCT in terms of image collection and data generation: time-domain OCT and frequency-domain OCT. The frequency-domain OCT has evolved over recent years to include spectral-domain OCT (SD-OCT) and sweptsource OCT (SS-OCT).${ }^{54}$ Recent studies have shown that retinal thickness measurement differences between SD-OCT and TD-OCT devices might exist. Currently published literature shows discrepancies regarding the optimal cut-off for central retinal thickness to define edema (Table 1).

Optical coherence tomography angiography (OCTA), provides deep observation of the blood flow of the retinal capillary layer. In patients with DR, many abnormalities in capillary flow density have been confirmed and microaneurysms from the deep capillary layer were demonstrated as well. These aspects could not be evaluated with FA and OCT. ${ }^{55}$ Five OCTA biomarkers, including foveal avascular zone area (FAZ-A), FAZ contour irregularity (FAZ-CI), vessel tortuosity (VT), average vessel caliber (AVC), and vessel density (VD), have been developed. ${ }^{56}$ In addition, the 
new OCT biomarkers of disorganization of retinal inner layers (DRIL) could be added to the prognostic ability of DME. ${ }^{57}$

The ETDRS defined the criteria for "clinically significant macular edema" as having any of the following features: thickening of the retina at or within 500 microns of the center of the macula; hard exudates at or within 500 microns of the center of the macula, if associated with thickening of the adjacent retina (excluding residual hard exudates remaining after the disappearance of retinal thickening); or retinal thickening at the one-disc area or larger, at any part within one disc diameter of the center of the macula. ${ }^{21}$

Consensus statement. The experts' panel agreed that the optimal cut-off for central retinal thickness depends on the machine used. According to a recent evidencebased review, the central retinal thickness ranged from $230 \mu \mathrm{m}$ to $300 \mu \mathrm{m}$ across different OCT machines, as presented in Table 1 . The experts' panel also agreed that biomarkers (such as preserved photoreceptor, hyperreflective spots by OCT, subfoveal neurosensory detachment, diffuse spongy edema, SRF, DRIL, and IS/OS junction) are important and aid in choosing the right treatment option. The experts' panel states that they depend on OCT, FA, location of edema, and VA for the diagnosis of DME in clinical practice. Also, they agreed that OCT is the preferred method to assess treatment response.

Management of DME. General preventive measures are essential to reduce the risk of DME development and progression. According to the American Diabetes Association, glycated hemoglobin (HbA1c) should not exceed 7\%, while the blood pressure and total lipids should be kept under 130/80 $\mathrm{mmHg}$ and $100 \mathrm{mg} / \mathrm{dL}$, respectively. ${ }^{58}$ For patients with clinically significant DME, the following options can be considered: retinal laser photocoagulation, anti-VEGFs, corticosteroids, and vitreoretinal surgery when necessary in cases of vitreomacular traction (VMT) or epiretinal membrane with DME.

Laser treatment of DME. The ETDRS group stated that the 2 most important techniques of laser photocoagulation in patients with DME are focal and grid laser techniques. Focal treatment is required for focal lesions located between $500 \mu \mathrm{m}$ and $3000 \mu \mathrm{m}$ from the center of the macula. A grid laser, in which mild power laser impacts are made with a spot size of $50 \mu \mathrm{m}$ to $200 \mu \mathrm{m}$, is required for more widespread and diffuse edema. ${ }^{59}$ Micropulse laser treatment is an alternative to the conventional continuous-wave laser for the treatment of retinal or macular diseases. In contrast to the conventional laser, the therapeutic effect of the subthreshold micropulse laser is not accompanied by thermal retinal damage. Micropulse treatment is applied in indications such as central serous chorioretinopathy, DME, or macular edema due to retinal vein occlusion. ${ }^{60}$ According to the findings of the ETDRS trial, laser photocoagulation demonstrated high efficacy in improving visual acuity and slowing the progression of visual field loss in patients with DME. These findings were further supported by recent trials that reported a superior benefit of laser photocoagulation over other options in patients with clinically significant DME. ${ }^{61,62}$

However, laser photocoagulation is not a complication-free procedure. A recent review by Reddy and Husain ${ }^{63}$ showed that pan-retinal laser photocoagulation may be associated with choroidal effusion, retinal detachment, macular hemorrhage, and visual field deficits. However, the risk of these complications is mainly related to inappropriate settings of laser parameters such as power and duration. ${ }^{64}$

Laser photocoagulation can be also used in combination with anti-VEGFs. Multiple studies reported that post-injection laser therapy is more effective than laser alone or anti-VEGFs alone on the VA of DME patients. ${ }^{65-67}$ Approximately $10 \%$ to $40 \%$ of patients who received post-injection laser gained $\geq 15$ letters improvement in their VA.

Overall, it should be noted that focal laser photocoagulation remains the gold standard treatment for focal DME and non-center involved macular edema. Its effect is most important after 2 years of follow-up. The grid laser photocoagulation technique may be indicated in cases of resistance or contraindications of anti-VEGF drugs. However, the laser is no more the gold standard for center-involved ME, even the focal photocoagulation. ${ }^{68}$

On the other hand, panretinal laser photocoagulation (PRP) is still a first-line therapy in the management of proliferative diabetic retinopathy (PDR). ${ }^{69}$ In patients with PDR but no central DME, PRP is considered the main treatment; while, in patients with PDR with non-central DME, a focal laser could be used with the PRP. If the PDR is presented with center-involved DME, anti-VEGF therapy is recommended. Then, PRP can be applied. ${ }^{70}$

The association between laser photocoagulation and intravitreal anti-VEGF drugs, despite their having an inferior effect compared to anti-VEGF alone, should be studied more extensively with 3 or more years of follow-up. New laser developments, such as the sub-threshold diode micropulse laser photocoagulation, seem promising but need to be studied more extensively. 
Anti-VEGF agents. Since the approval of anti-VEGF agents for the treatment of age-related macular degeneration in 2006, their use has grown exponentially to include a wide range of retinal and anterior segment diseases. ${ }^{71,72}$ With regard to DME, 2 anti-VEGF agents are currently approved by the Saudi Food and Drug Administration, namely ranibizumab and aflibercept.

Ranibizumab, the first approved anti-VEGF agent, is a humanized monoclonal antibody that acts by interrupting the functions of all isoforms of VEGF. Previous reports indicated that ranibizumab is effective in decreasing macular thickness and choroidal neovascularization. ${ }^{73}$ In the pivotal RESTORE study, ranibizumab was compared, either alone or in combination with laser, to laser photocoagulation for the treatment of DME. Both ranibizumab monotherapy and a combination of ranibizumab with laser therapy exhibited superior efficacy compared to laser treatment in the one-year change in VA and macular thickness, though no significant difference between ranibizumab monotherapy and a combination of ranibizumab with laser therapy was reported. ${ }^{74}$

The results of several randomized trials using ranibizumab are available. They include a comparison with sham injection (RESOLVE, RISE, and RIDE), comparison with laser treatment (READ-2 and RESTORE), and comparison with prompt and deferred laser (DRCR.net Protocol I). All these studies have shown that intravitreal ranibizumab monotherapy is superior to laser monotherapy or intravitreal triamcinolone and that additional laser (prompt or deferred) combined with intravitreal ranibizumab does not necessarily improve vision in DME. ${ }^{75}$

Aflibercept is a soluble protein that binds extracellularly to VEGF receptors and can interfere with all 6 VEGF proteins (VEGF trap). ${ }^{76}$ DA VINCI (DME and VEGF trap-eye: investigation of clinical impact), a Phase II study, compared different doses of aflibercept (VEGF Trap) with laser over a period of one year. At one year, more proportions of patients who received aflibercept gained $>10$ and $>15$ letters than those who received laser alone. ${ }^{77}$ The phase III parallel study; VIVID-DME and VISTA-DME, compared 2 doses of aflibercept ( 2 mg every 4 weeks, $2 q 4$, and 2 mg every 8 weeks, 2q8) after the initial 5 monthly injections with laser treatment; both doses of aflibercept were found to be superior to laser. ${ }^{76}$

The anti-VEGF treatment schedule usually involves a loading dose of monthly injections for 3 months followed by an injection every 4 to 6 weeks, if necessary. ${ }^{78}$ Since it requires many visits for frequent injections, we reported different treatment regimens, from monthly treatment to pro re nata $(\mathrm{PRN})$ and treat and extend (TE). In TE regimens, the interval of follow-up visits should be adjusted based on the clinical course of DME. If the patient has not experienced any sign of active disease, intervals will be extended. While if there is any sign of edema, the next interval will be shortened. Therefore, TE may also be called pro-active, while the PRN protocol is reactive. Treat and extend regimen has been proven to be superior to the other regimens in terms of better visual outcomes despite fewer injections. ${ }^{79}$

A considerable proportion of patients remain unresponsive to anti-VEGF agents (Table 2), even with monthly injections for up to 2 years. According to the Diabetic Retinopathy Clinical Research Network (DRCRnet) protocol I, almost half of the patients on ranibizumab failed to achieve $\geq 2$-vision-line improvement and $40 \%$ still had macular edema $\geq 250 \mu \mathrm{m}$ after 2 years. ${ }^{80}$ In patients who are unresponsive to first-line anti-VEGF therapy or have an unsatisfactory response, a switch to another class of treatment may be considered. ${ }^{81}$

Corticosteroids. Owing to the anti-inflammatory effect of corticosteroids, it is considered an important option in the management of DME. Switching to steroids is recommended in patients who are nonresponders to anti-VEGF agents. Besides, some patients can benefit from steroids as first-line therapy. ${ }^{82}$

Intravitreal corticosteroids can improve the outcomes of DME by inhibiting the release of inflammatory mediators and leukostasis, which are significant contributors to the development of DME. ${ }^{28}$ Initially, intravitreal injection of triamcinolone acetonide (TA) was studied and exhibited significant improvements in visual and anatomical outcomes among patients with DME. ${ }^{83-85}$ Triamcinolone acetonide combined with laser therapy was found to be as effective as ranibizumab plus laser therapy in pseudophakic eyes. ${ }^{86}$

However, elevated intraocular pressure (IOP) and cataract are major concerns during triamcinolone acetonide injections; Gillies et $\mathrm{a}^{87}$ reported that $44 \%$ of the patients receiving TA injections required glaucoma medications, and $54 \%$ underwent cataract surgery. ${ }^{86}$ The sustainability of the beneficial effect of triamcinolone acetonide injection may be considered as another limitation for its use in patients with refractory DME. ${ }^{88}$ Nevertheless, intravitreal triamcinolone acetonide has not yet been approved for DME and its use is mainly off-label. ${ }^{89}$

Dexamethasone implants and fluocinolone acetonide are new options found to be efficient in various studies. ${ }^{90}$ Dexamethasone intravitreal implant (DEX implant; 
Table 2 - Summary of real-life studies supporting the safety and efficacy of anti-VEGFs.

\begin{tabular}{|c|c|c|c|c|c|c|c|c|c|c|c|c|}
\hline Study & Drugs & Study design & $\begin{array}{c}\text { Patient } \\
\text { status }\end{array}$ & $\begin{array}{c}\text { Number } \\
\text { (eyes) }\end{array}$ & $\begin{array}{c}\text { Follow- } \\
\text { up } \\
\text { (months) }\end{array}$ & $\begin{array}{l}\text { Mean } \\
\text { number } \\
\text { IVI }\end{array}$ & $\begin{array}{c}\text { Baseline } \\
\text { VA } \\
\text { (letters) }\end{array}$ & $\begin{array}{c}\text { Final } \\
\text { VA } \\
\text { (letters) }\end{array}$ & $\begin{array}{l}\text { Mean } \\
\text { VA gain } \\
\text { (letters) }\end{array}$ & $\begin{array}{l}\text { Mean } \\
\text { CRT } \\
\text { reduction }\end{array}$ & IOP & $\begin{array}{c}\text { Cataract } \\
\text { progression/ } \\
\text { extraction }\end{array}$ \\
\hline $\begin{array}{l}\text { Bahrami et } \\
\mathrm{al}^{91}\end{array}$ & Aflibercept & Prospective & Non-Naïve & 43 & 6 & 5 & 67.8 & 71 & 3.2 & $37 \mu \mathrm{m}$ & $\begin{array}{c}0 \%(\mathrm{IOP} \geq \\
25 \mathrm{mmHg} \text { or } \\
\text { a rise of IOP } \\
\geq 10 \mathrm{mmHg})\end{array}$ & $0 \%$ \\
\hline Kaiho et $\mathrm{a}^{92}$ & Aflibercept & ND & Non-Naïve & 51 & 12 & 3.8 & 65.5 & 70 & 4.5 & ND & ND & ND \\
\hline Aksoy et $\mathrm{al}^{93}$ & Bevacizumab & Prospective & Naïve & 20 & 6 & 6 & 51 & 55.5 & 4.5 & $210 \mu \mathrm{m}$ & $\begin{array}{c}10 \%(\mathrm{IOP}>21 \\
\mathrm{mmHg})\end{array}$ & $2.50 \%$ \\
\hline Fong et $\mathrm{a}^{94}$ & Bevacizumab & Retrospective & $\begin{array}{c}\text { Mixed } \\
\text { (65\% naive, } \\
30 \% \text { laser, } \\
4 \% \text { steroid) }\end{array}$ & 309 & 24 & 3.1 & 57 & 62.3 & 5.3 & ND & ND & ND \\
\hline Güler et $\mathrm{a}^{95}$ & Bevacizumab & Prospective & ND & 20 & 9 & 6 & 38 & 42 & 4 & $\begin{array}{c}295 \pm 42 \\
\mu \mathrm{m}\end{array}$ & ND & $0 \%$ \\
\hline Koc et $\mathrm{al}^{96}$ & Bevacizumab & Retrospective & Naïve & 90 & 24 & 4.9 & 45.2 & 48.7 & 3.5 & $\begin{array}{l}74.7 \pm \\
133.9\end{array}$ & ND & $13.70 \%$ \\
\hline $\begin{array}{l}\text { Riazi-Esfahani } \\
\text { et a } \mathrm{l}^{77}\end{array}$ & Bevacizumab & $\mathrm{ND}$ & Naïve & 46 & 6 & & 67.5 & 72.5 & 5 & $\begin{array}{c}102 \pm \\
108\end{array}$ & $\begin{array}{c}6.5 \% \text { (IOP } \\
\geq 21 \mathrm{mmHg} \text { ) }\end{array}$ & 0 \\
\hline Cheema et al ${ }^{98}$ & $\begin{array}{c}\text { Bevacizumab } \\
\text { (diffuse) }\end{array}$ & Retrospective & ND & 28 & 6 & 1.3 & 44 & 45 & 1 & ND & ND & ND \\
\hline Ciulla et al ${ }^{99}$ & Ranibizumab & Retrospective & Non-Naïve & 33 & 12 & 6 & 59 & 63 & 4 & $44 \mu \mathrm{m}$ & ND & ND \\
\hline Egan et al ${ }^{100}$ & Ranibizumab & Retrospective & $\begin{array}{c}\text { Mixed } \\
(49.6 \% \\
\text { Naive) }\end{array}$ & 3103 & 24 & 5.4 & 51.1 & 52.5 & 1.4 & ND & ND & ND \\
\hline
\end{tabular}

IVI: intravitreal injection, VA: visual acuity, CR: central retnal thickness, IOP: intra-ocular pressure, ND: not determined/detected

Ozurdex; Allergan, Inc., Irvine, CA) is a device that maintains a sustained release of dexamethasone for up to 6 months. Currently, dexamethasone implants are approved for the treatment of DME. ${ }^{101}$

In the pivotal MEAD trials, a greater percentage of patients with a $\geq 15$-letter gain of best corrected visual acuity (BCVA) from baseline was observed in the dexamethasone implant groups than in the sham arm. A similar finding was observed for CRT. ${ }^{102}$ In the PLACID trial, a higher percentage of patients in the dexamethasone arm achieved at least 10 letters than the laser monotherapy arm. The percentage of patients requiring glaucoma medications was significantly higher in the dexamethasone arm. ${ }^{103}$

Data from real-life studies further supported the safety and efficacy of dexamethasone implants in naïve and non-naive patients. Dexamethasone implants are thought to be associated with lower risks of glaucoma and cataracts. Dexamethasone implants have lower lipophilic properties than other corticosteroids, which render its lower binding affinity to the trabecular meshwork. Thus, dexamethasone implants are thought to be associated with lower risks of glaucoma and cataract (Table 3). ${ }^{104}$ Early identification and treatment of non-responders are critical in the setting of DME as long-standing edema may lead to macular ischemia, fibrosis, and atrophy. ${ }^{105}$ Current evidence suggests that early poor anatomic (reduction of $<20 \%$ in CRT) and functional (less than 5 letter gain in BCVA) response to anti-VEGF is associated with less favorable long-term anatomic and functional outcomes. ${ }^{106-107}$ Thus, it was proposed that early shifting from anti-VEGF agents in partial responders can result in better outcomes. Cicinelli et al, ${ }^{108}$ studied 45 patients who were shifted to $0.7 \mathrm{mg}$ dexamethasone implant after 3 injections of ranibizumab. Poor responders to ranibizumab exhibited a clinically significant reduction in CRT and better improvement in BCVA than patients with good response. More recently, Busch et $\mathrm{al}^{109}$ compared the early switch to dexamethasone implant versus continuing anti-VEGF therapy in refractory DME. After 12 months of treatment, the results indicated better functional and anatomic outcomes in the early switch group than in the anti-VEGF group.

The possibility of cataract development following corticosteroid therapy is not present in patients with pseudophakic eyes. Thus, dexamethasone implants may be preferred over other options for DME management in patients with pseudophakic eyes. In a prospective 
Table 3 - Summary of real-life studies supporting the safety and efficacy of dexamethasone implants.

\begin{tabular}{|c|c|c|c|c|c|c|c|c|c|}
\hline Study & Study design & $\begin{array}{l}\text { Patient } \\
\text { status }\end{array}$ & $\begin{array}{c}\text { Number } \\
\text { (eyes) }\end{array}$ & $\begin{array}{c}\text { Follow-up } \\
\text { (months) }\end{array}$ & $\begin{array}{l}\text { Mean } \\
\text { number } \\
\text { IVI }\end{array}$ & $\begin{array}{c}\text { Mean } \\
\text { VA gain } \\
\text { (letters) }\end{array}$ & $\begin{array}{l}\text { CRT } \\
\text { reduction } \\
\text { by OCT }\end{array}$ & IOP & $\begin{array}{c}\text { Cataract } \\
\text { progression/ } \\
\text { extraction }\end{array}$ \\
\hline $\begin{array}{l}\text { Chatziralli } \\
\text { et } \mathrm{al}^{110}\end{array}$ & Prospective & Non-naive & 54 & 12 & 2.1 & 5.2 & $181 \mu \mathrm{m}$ & $5.6 \%(\mathrm{IOP}>20 \mathrm{mmHg})$ & $4.30 \%$ \\
\hline $\begin{array}{l}\text { Cicinelli et } \\
\mathrm{al}^{108}\end{array}$ & Retrospective & Non-naive & 45 & 12 & 1.9 & 5.8 & $29 \mu \mathrm{m}$ & $18.4 \%(\mathrm{IOP} \geq 20 \mathrm{mmHg})$ & $20 \%$ \\
\hline Iglicki et $\mathrm{al}^{111}$ & Retrospective & Non-naive & 59 & 24 & 3.1 & 8.5 & ND & $7.10 \%$ & ND \\
\hline Guigou et $\mathrm{al}^{112}$ & Retrospective & $\begin{array}{c}\text { Mixed } \\
(20.5 \% \\
\text { de naive })\end{array}$ & 78 & 6 & 1.2 & 8.0 & $145.2 \mu \mathrm{m}$ & $\begin{array}{c}11.7 \%(\mathrm{IOP}>25 \mathrm{mmHg}) \\
13.3 \%(\text { rise of IOP }>10 \\
\mathrm{mmHg} \text { ) }\end{array}$ & $0 \%$ \\
\hline $\begin{array}{l}\text { Pareja-Rios et } \\
\mathrm{al}^{113}\end{array}$ & Retrospective & Naive & 113 & 12 & 1.4 & 9.7 & $32 \mu \mathrm{m}$ & $\begin{array}{c}4 \%(\text { rise of IOP }>10 \\
\mathrm{mmHg})\end{array}$ & ND \\
\hline Bellocq et al ${ }^{114}$ & Prospective & $\begin{array}{c}\text { Mixed } \\
\text { (73\% naive) }\end{array}$ & 37 & 6 & 1.5 & 10.1 & $206 \mu \mathrm{m}$ & $\begin{array}{c}14 \%(\mathrm{IOP}>25 \mathrm{mmHg}) \\
3 \%(\mathrm{IOP}>35 \mathrm{mmHg}) 8 \% \\
\text { (rise of IOP > } 10 \mathrm{mmHg} \text { ) }\end{array}$ & ND \\
\hline Malcles et $\mathrm{al}^{115}$ & Retrospective & $\begin{array}{c}\text { Mixed } \\
\text { (27\% naive) }\end{array}$ & 128 & 36 & 3.6 & 9.5 & $138 \mu \mathrm{m}$ & $\begin{array}{c}10.2 \%(\mathrm{IOP}>25 \mathrm{mmHg}) \\
2.3 \%(\mathrm{IOP}>35 \mathrm{mmHg}) \\
19 \%(\text { rise of } \mathrm{IOP}>10 \\
\mathrm{mmHg})\end{array}$ & ND \\
\hline $\begin{array}{l}\text { Scaramuzzi et } \\
\mathrm{al}^{116}\end{array}$ & Retrospective & $\begin{array}{l}\text { Mixed } \\
\text { (7\% naive) }\end{array}$ & 15 & 12 & 2.0 & 8.5 & $240 \mu \mathrm{m}$ & $20 \%$ & $8.30 \%$ \\
\hline
\end{tabular}

IVI: intravitreal injection, VA: visual acuity, CRT: central retnal thickness, IOP: intra-ocular pressure, ND: not determined/detected, OCT: optical coherence tomography

comparative study by Ozsaygili and Duru, ${ }^{117}$ they observed that both dexamethasone implant and aflibercept were effective and safe in treatment-naive DME patients with an inflammatory phenotype. In pseudophakic eyes, the functional superiority of aflibercept ceased to exist, and the low number of injections in the dexamethasone implant group was seen as an advantage. ${ }^{117}$

Provided with evidence that supports the efficacy of corticosteroids in DME, the 2017 guideline of the European Society of Retina Specialists recommended the use of corticosteroids as second-line options in patients who remain unresponsive after 3 to 6 injections of anti-VEGF agents. ${ }^{82}$ However, a corticosteroid may be considered as the first-line option in patients with cardiovascular morbidities, very thick edema, having inflammatory biomarkers on OCT (DRIL, Hyperreflective foci) that reveal a long-standing inflammation unlikely to respond to a few anti-VEGF injections or patients who are not willing to present monthly for injection.

On the other hand, diabetic patients have both a higher prevalence of early cataract, with a consequent need for cataract surgery. Managing a patient with preexisting DME who underwent cataract surgery is challenging. Several treatment strategies have been investigated in order to prevent worsening the DME after cataract surgery. While, in the presence of DME during the cataract surgery, combining phacoemulsification surgery with an intravitreal injection of anti-VEGF or steroids before the cataract surgery is recommended to prevent macular edema worsening after the surgery.

Consensus statement. International guidelines recommend monthly examination of patients after anti-VEGF injection for the assessment of treatment response. However, the experts' panel stated that OCT-based assessment should be carried out at least every 3 months after loading doses of anti-VEGF. Our assessment recommendation is based on the TE strategy. We prefer the TE strategy due to the high cost of the monthly visit, difficulty for some old patients, and better results of TE shown in real-world practice. ${ }^{118}$

The experts' panel stipulated that the following criteria define the improvement of anti-VEGF treatment: if VA improved by more than 5 letters or the central subfield thickness on OCT improved by more than $20 \%$ since the last assessment before treatment as per the protocol I. ${ }^{107}$

The experts' panel stipulated that the following criteria define non-responders to anti-VEGF: signs of massive edema, reduction of $<20 \%$ in CRT or macular volume, and no or $<5$ letter improvement in VA after initial loading course (as per protocol I sub-analysis). ${ }^{115}$ The experts' panel stated that, in their clinical practice, 
between $20-30 \%$ of patients are non-responders according to these criteria.

They also agreed that 3 injections were sufficient to identify non-responders. After this, switching can be considered accordingly.

They stated that they consider shifting to another anti-VEGF in case of suboptimal response to the current anti-VEGF. The utility of switching between anti-VEGF agents is debatable. Factors other than potency, including price and availability, may be considered in switching decisions.

The experts' panel agreed that early treatment with DME is recommended to achieve a better prognosis. Steroid injection can be beneficial in these types of patients: patients who are non-responders after 3 to 6 injections of anti-VEGF injections, patients with pseudophakic eyes, post-vitrectomy patients, patients not willing to be injected on monthly treatment, pregnant patients, and patients with recent (3 to 6 months) cardiovascular (CV) or cerebrovascular events. Specifically, the experts' panel stated that they will consider steroids in controlled glaucoma patients who are non-responders to anti-VEGF therapy. They also stated that they would prefer a dexamethasone implant as a first-line option over triamcinolone. For steroids, the experts agreed that the response should be evaluated after 2-3 months.

The experts agreed that most of the women who develop DME during pregnancy pass through a spontaneous post-partum resolution and do not require implants. ${ }^{19}$ However, the experts recommend using dexamethasone implant for women who developed DME before pregnancy.

The experts' panel agreed that patients with small DME and good VA could be observed closely, instructed for strict systemic control of DM and HTN, and start anti-VEGF therapy only if their case aggravated (as per protocol V). ${ }^{120}$

The experts' panel agreed that they need to provide courses and workshops for ophthalmologists, who are dealing with DME to increase their awareness on disease management. They also highlighted the importance of establishing unified medical records that can ease the individualization of management based on personal medical history.

Algorithm of treatment. In this section, we provide the most updated (until the end of 2019) consensuses from the US and Europe. The American Delphi Panel ${ }^{121}$ highlighted that the non-responders are defined as the failure of BCVA to improve to $20 / 40$ or better because of edema after 3 to 6 monthly injections, or a lee than $50 \%$ reduction in excess macular thickness on OCT after 3 to 4 monthly injections. They also highlighted the role of combination therapy. Therefore, if a patient is a non-responder to anti-VEGFs, they shift to steroids, and if they do not respond as well, they use the combination. They also mentioned that the ideal patients to shift for steroids are patients who have a lack of anatomical response, lack of improvement in BCVA, treatment burden, and recent strokes. In addition, they saw that OCT results are more valuable than FA. They also highlighted the criteria of non-responders and settled the criteria of eligible patients for steroids, which includes: patients with vitrectomized eye, patients planned for cataract surgery, those with persistent DME, inadequate responder to anti-VEGF who is pseudophakic, inadequate responder to anti-VEGF who is phakic and older than 60 years old, inadequate responders to anti-VEGF who is phakic and younger than 60 years old, resistant to laser photocoagulation, and patients with successful filtration to controlled IOP.

The Spanish Delphi panel was recently published. The experts' panel agreed that intravitreal dexamethasone implants are useful in the treatment of patients with DME with different profiles. ${ }^{122}$ Examples of such patients include pseudophakic, poor adherents, vitrectomized, candidates for cataract surgery, patients with a high inflammatory component, and with a history of cardiovascular events. The use of intravitreal dexamethasone reduces the number of visits and facilitates compliance. Inadequate response to anti-VEGF therapy is defined as $<10 \%$ reduction in CRT or $<5$ letters improvement in BCVA. Experts thought that the switch from anti-VEGF therapy to intravitreal dexamethasone implants should be performed preferably after 3 injections. In addition, PRN treatment provides better results in DME patients as it helps to prevent undertreatment.

Italian experts also published a Delphi-based consensus. ${ }^{123}$ The experts' panel agreed that dexamethasone intravitreal implants are considered to be a valid first-line alternative to treatment with an anti-VEGF agent and should be the first choice in pseudophakic and vitrectomized patients. The PRN regimen was deemed appropriate for retreatment with dexamethasone intravitreal implants, while a 6-month waiting period was not considered suitable. Among steroid treatments, dexamethasone intravitreal implants were considered to have the best ocular tolerability. In patients with persistent macular edema after the loadingphase treatment with anti-VEGF agents, a consensus was reached that clinicians should consider switching therapy to dexamethasone intravitreal implants after 3 to 5 injections. Moreover, dexamethasone 
intravitreal implants can reduce the treatment burden for individuals who are unable to cope with the more intensive treatment regimen required by anti-vascular endothelial growth factor therapy.

Recently, French experts also published a Delphibased consensus. ${ }^{124}$ The experts agreed that anti-VEGF therapy is the current first-line treatment for DME. Steroids also represent a valid treatment option in the management of naive DME, and their efficacy has also been confirmed in several studies. Inadequate response to anti-VEGF therapy is defined as a $<20 \%$ reduction in CRT, $<5$ letters improvement in BCVA, or partial or complete failure or recurrence too frequent. In such cases, switching to dexamethasone intravitreal implants can be considered.

Consensus statement. The experts' panel agreed to categorize the treatment algorithm according to the presence of central macula involvement.

a) The cardiovascular or cerebrovascular event has to be recent, that is, within the last 3 to 6 months. If it is not recent, then steroids might not be the only available line of treatment; therefore, they advise to include the word RECENT in the definition. b) Within the class of steroids, dexamethasone implants should be used first, while fluocinolone can be considered in non-steroid responders. ${ }^{82}$ They should involve the patient in the decision of choosing the appropriate treatment option based on many factors, including those where affordability could play a role.

c) In the phakic eyes, the experts' panel stated that anti-VEGF agents are the first choice, and steroids can be a second option for patients not responding to anti-VEGF agents. Patients may be informed on the risk of cataract surgery following steroid injections, and IOP must be monitored.

d) For patients with no recent major CV events, the experts' panel agreed not to classify them into phakic or pseudo-phakic eyes. They will be considered as a single group to initially take anti-VEGF agents for 3 months; the evaluation should take place subsequently. In the case of responders, anti-VEGF agents should be continued; for non-responders, you have to choose to either switch to steroids or continue on anti-VEGF agents.

e) Tractional macular edema is characterized by an incomplete posterior vitreous detachment with

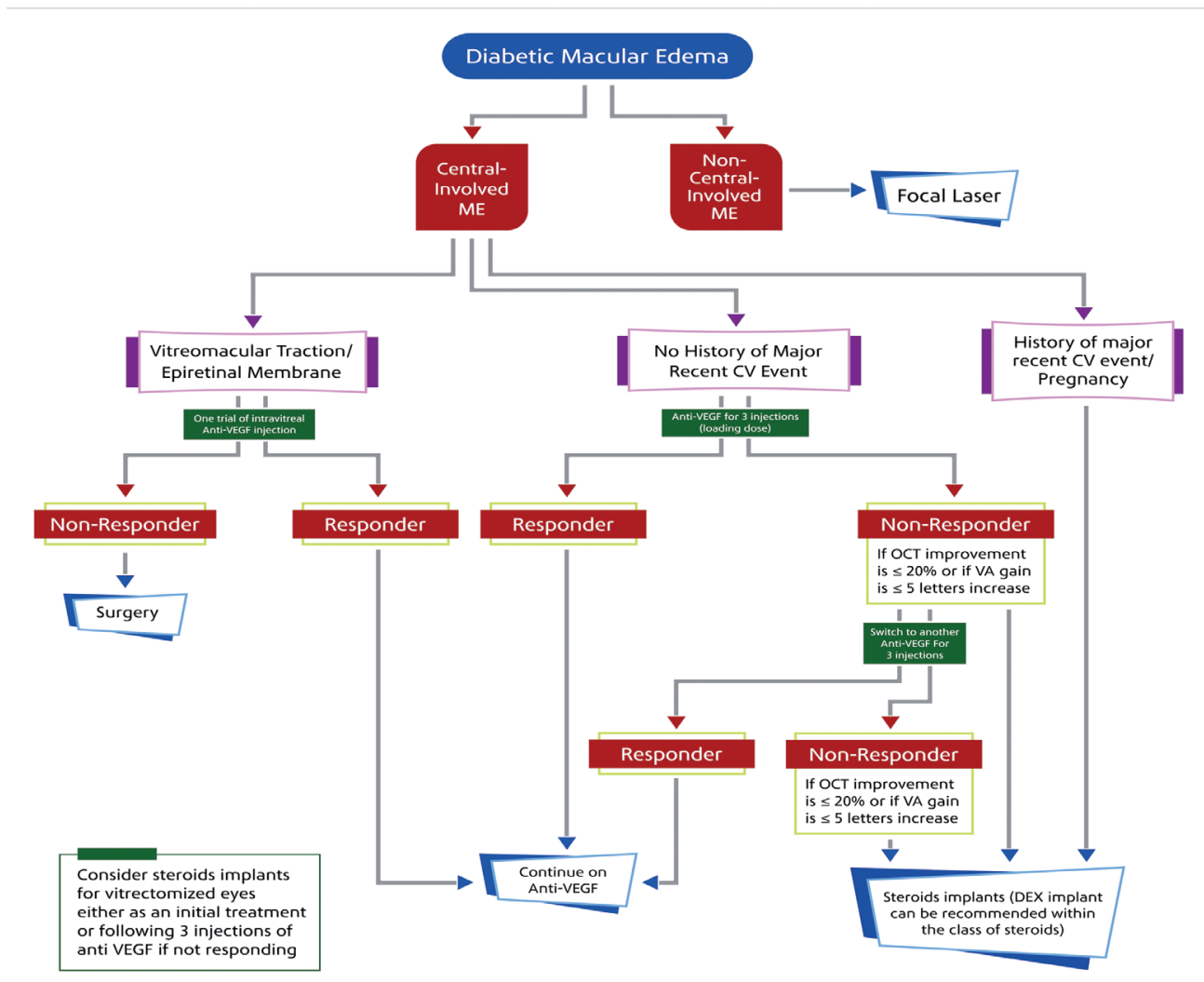

Figure 1 - Treatment algorithm for diabetic macular edema 
the persistently adherent vitreous humor exerting a tractional pull on the macula and resulting in morphologic alterations and consequent visual decline.

f) The experts' panel recommends that the "tractional macula edema" term should be replaced by VMT or vitreomacular adhesion (VMA), as these are more precise terms. Vitreomacular adhesion, as a definition, is usually used as a term to describe the nonedematous eyes, but for VMT, edema is the characteristic pathogenesis of DME. Therefore, the experts agreed to remove VMA and put only VMT.

g) The experts' panel agreed that the initial treatment of VMT should consist of one trial of intravitreal injection of anti-VEGF agents.

h) The experts' panel recommends that dexamethasone implants be the first-line steroid for anti-VEGF non-responders, as triamcinolone acetonide is being used as an off-label indication and it is associated with a high rate of complications. Fluocinolone can be reserved as a second-line steroid. The final algorithm is presented in Figure 1.

Discussion. Diabetic macular edema is a visionthreatening complication of DR and a major cause of vision loss worldwide. Ocular treatments include retinal laser photocoagulation, anti-VEGF agents, intravitreal corticosteroids, and vitreoretinal surgery when necessary.

A growing body of evidence suggests a critical role of inflammatory mediators/processes in the pathogenesis of DME, especially among chronic patients or those who show an inadequate response to anti-VEGF agents. ${ }^{125}$ Recently, several OCT-based inflammatory biomarkers, such as hyperreflective retinal spots (HRS) and subfoveal neuroretinal detachment (SND), were investigated as predictive factors for response in patients with resistant DME. ${ }^{126}$ Spectral domain-OCT provides promising parameters to predict the response to dexamethasone implants; however, further studies are still needed.

The subclinical DME is a state in which macular thickening can be visualized by OCT quantitatively, yet it can not be seen on the clinical examination. In an observational study conducted by Elman et al, ${ }^{127}$ one-fourth to one-half of the subclinical DME patients has progressed to clinically significant DME within 2 years of follow-up. Our recommendation for the management of Subclinical DME is composed mainly of prevention of its progression to more definite thickening. A regular follow-up visit, glycemic control, and strict control of the other risk factors (as hypertension and smoking) are highly recommended.

Current anti-VEGF treatments require frequent injections and monitoring, causing a significant burden on patients and healthcare systems, with a financial impact and reduction in patient quality of life. ${ }^{128}$ In a 2017 report, Ramu et al ${ }^{129}$ reported a statistically significant improvement in treatment satisfaction in patients with DME treated with dexamethasone intravitreal implants.

Non-proliferative DR (NPDR) patients can progress into 2 different clinical pathways; either to the exudate formation stage (DME) or to the proliferative changes of DR. ${ }^{130}$ In patients with severe NPDR who progressed to the proliferative stage of DR, the authors recommend using anti-VEGF injection combined with PRP which used to be the first-line treatment.

Diabetic macular edema management has been evolving over the last few years due to improvement in the imaging techniques and the introduction of new medications. Therefore, our guidelines might be updated in the future according to the evolving evidence.

In conclusion, for patients with no central macular involvement, laser photocoagulation is recommended as the first-line option. Patients with central macular involvement and no recent history of CVS should be offered anti-VEGF agents as the first-line option. In the case of non-responders, switching to another anti-VEGF agent or steroids should be considered.

Acknowledgment. We would like to thank all the Saudi Retina Group participants. Saudi Retina Group would like as well to thank Allergan pharmaceuticals - KSA for facilitating the logistics of consensus development meetings. Allergan-KSA played no role in gathering, analyzing, or interpreting the manuscript. Also, we would like to thank $R A Y$ contract research organization for the editorial support and Editage (www.editage.com) for English language editing.

\section{References}

1. Kaiser AB, Zhang N, Der Pluijm WVAN. Global prevalence of type 2 diabetes over the next ten years (2018-2028). Diabetes 2018; 67 (Supplement 1): 202-LB.

2. International Diabetes Federation. IDF Diabetic Atlas 7 th Edition. Int Diabetes Fed 2015; 39: 1-144.

3. World Health Organization. Diabetes Key Fact [ Updated 2020 June 8. Cited 2020 November 20] Available from URL: https://www.who.int/news-room/fact-sheets/detail/diabetes

4. Chawla A, Chawla R, Jaggi S. Microvasular and macrovascular complications in diabetes mellitus: Distinct or continuum? Indian J Endocrinol Metab 2016; 20: 546-551.

5. Kalofoutis C, Piperi C, Kalofoutis A, Harris F, Phoenix D, Singh J. Type II diabetes mellitus and cardiovascular risk factors: Current therapeutic approaches. Exp Clin Cardiol 2007; 12: 17-28. 
6. Orasanu G, Plutzky J. The pathologic continuum of diabetic vascular disease. J Am Coll Cardiol 2009; 53: S35-S42.

7. Klein R, Knudtson MD, Lee KE, Gangnon R, Klein BEK. The Wisconsin epidemiologic study of diabetic retinopathy XXII. The twenty-five-year progression of retinopathy in persons with type 1 diabetes Ophthalmology 2008; 115: 1859-1868.

8. Zhang X, Zeng H, Bao S, Wang N, Gillies MC. Diabetic macular edema: new concepts in patho-physiology and treatment. Cell Biosci 2014; 4: 27.

9. Kempen JH, O'Colmain BJ, Leske MC, Haffner SM, Klein R, Moss SE, et al. The prevalence of diabetic retinopathy among adults in the United States. Arch Ophthalmol 2004; 122: 552-563.

10. White NH, Sun W, Cleary PA, Tamborlane W V, Danis RP, Hainsworth DP, et al. Effect of prior intensive therapy in type 1 diabetes on 10-year progression of retinopathy in the DCCT/ EDIC: comparison of adults and adolescents. Diabetes 2010; 59: $1244-1253$.

11. Bhagat N, Grigorian RA, Tutela A, Zarbin MA. Diabetic macular edema: pathogenesis and treatment. Surv Ophthalmol 2009; 54: 1-32.

12. Zhang X, Bao S, Lai D, Rapkins RW, Gillies MC. Intravitreal triamcinolone acetonide inhibits breakdown of the bloodretinal barrier through differential regulation of vegf-a and its receptors in early diabetic rat retinas. Diabetes 2008; 57 : 1026-1033.

13. Leal EC, Manivannan A, Hosoya KI, Terasaki T, Cunha-Vaz J, Ambro'sio AF, et al. Inducible nitric oxide synthase isoform is a key mediator of leukostasis and blood-retinal barrier breakdown in diabetic retinopathy. Investig Opthalmology Vis Sci 2007; 48: 5257.

14. Gundogan FC, Yolcu U, Akay F, Ilhan A, Ozge G, Uzun S. Diabetic macular edema: a short review. Pakistan J Med Sci 1969; 32: 505-510.

15. Gundogan FC, Yolcu U, Akay F, Ilhan A, Ozge G, Uzun S. Diabetic macular edema. PakJ Med Sci 2016; 32: 505-510.

16. Varley MP, Frank E, Purnell EW. Subretinal neovascularization after focal argon laser for diabetic macular edema. Ophthalmology 1988; 95: 567-573.

17. Guyer DR, D'Amico DJ, Smith CW. Subretinal fibrosis after laser photocoagulation for diabetic macular edema. Am J Ophthalmol 1992; 113: 652-656.

18. Alkhamis A. Health care system in Saudi Arabia: An overview. East Mediterr Heal J 2012; 18: 1078-1079.

19. Al-Rubeaan K, Abu El-Asrar AM, Youssef AM, Subhani SN, Ahmad NA, Al-Sharqawi AH, et al. Diabetic retinopathy and its risk factors in a society with a type 2 diabetes epidemic: A Saudi National Diabetes Registry-based study. Acta Ophthalmol 2015; 93: E140-E147.

20. Modi YS, Pecen PE, Schachat AP. Management of diabetic macular edema. In: Singh PR, editor. Managing Diabetic Eye Disease in Clinical Practice. Switzerland (AG); Springer International Publishing: 2015. p. 81-103.

21. Early Treatment Diabetic Retinopathy Study Research Group. Photocoagulation for diabetic macular edema. Early treatment diabetic retinopathy study report no. 1. Early treatment diabetic retinopathy study research group. Arch Ophthalmol 1985; 103: 1796-1806.

22. Iaccarino G, Ciccarelli M, Sorriento D, Galasso G, Campanile A, Santulli G, et al. Ischemic neoangiogenesis enhanced by $\beta 2$ - adrenergic receptor overexpression. A novel role for the endothelial adrenergic system. Circ Res 2005; 97: 1182-119.
23. Williams KP, Steinle JJ. Maintenance of beta-adrenergic receptor signaling can reduce fas signaling in human retinal endothelial cells. Exp Eye Res 2009; 89: 448-455.

24. Melder RJ, Koenig GC, Witwer BP, Safabakhsh N, Munn LL, Jain RK. During angiogenesis, vascular endothelial growth factor and basic fibroblast growth factor regulate natural killer cell adhesion to tumor endothelium. Nat Med 1996; 2: 992-997.

25. Park HYL, Kim JH, Park CK. Neuronal cell death in the inner retina and the influence of vascular endothelial growth factor inhibition in a diabetic rat model. Am J Pathol 2014; 184: 1752-1762.

26. The Royal College of Ophthalmologists. Clinical Guidelines for Diabetic Retinopathy: A Summary. [Updated 2012. Cited 2021 January 9]; Available from: https://www.rcophth.ac.uk/ wp-content/uploads/2014/12/2013-SCI-301-FINAL-DRGUIDELINES-DEC-2012-updated-July-2013.pdf

27. Romero-Aroca P, Baget-Bernaldiz M, Pareja-Rios A, LopezGalvez M, Navarro-Gil R, Verges R. Diabetic macular edema pathophysiology: vasogenic versus inflammatory. $J$ Diabetes Res 2016; 2016: 2156273.

28. Chung YR, Kim YH, Ha SJ, Byeon HE, Cho CH, Kim JH, et al. Role of inflammation in classification of diabetic macular edema by optical coherence tomography. J Diabetes Res 2019; 2019: 8164250 .

29. Noma H, Mimura T, Yasuda K, Shimura M. Role of inflammation in diabetic macular edema. Ophthalmologica 2014; 232: 127-135.

30. Yau JWY, Rogers SL, Kawasaki R, Lamoureux EL, Kowalski JW, Bek T, et al. Global prevalence and major risk factors of diabetic retinopathy. Diabetes Care 2012; 35: 556-564.

31. Lee R, Wong TY, Sabanayagam C. Epidemiology of diabetic retinopathy, diabetic macular edema and related vision loss. Eye Vis 2015; 2: 17.

32. Paulus YM, Gariano RF. Diabetic retinopathy: a growing concern in an aging population. Geriatrics 2009; 64: 16-20.

33. Varma R, Bressler NM, Doan Q V, Gleeson M, Danese M, Bower JK, et al. Prevalence of and risk factors for diabetic macular edema in the United States. JAMA Ophthalmol 2014; 132: 1334-1340.

34. Li JQ, Welchowski T, Schmid M, Letow J, Wolpers C, PascualCamps I, et al. Prevalence, incidence and future projection of diabetic eye disease in Europe: a systematic review and metaanalysis. Eur J Epidemiol 2019; 35: 11-23.

35. Wong TY, Cheung N, Tay WT, Wang JJ, Aung T, Saw SM, et al. Prevalence and risk factors for diabetic retinopathy. Ophthalmology 2008; 115: 1869-1875.

36. Dehghan MH, Katibeh M, Ahmadieh H, Nourinia R, Yaseri $\mathrm{M}$. Prevalence and risk factors for diabetic retinopathy in the 40 to 80 year-old population in Yazd, Iran: The Yazd eye study. J Diabetes 2015; 7: 139-141.

37. Pedro RA, Ramon SA, Marc BB, Juan FB, Isabel MM. Prevalence and relationship between diabetic retinopathy and nephropathy, and its risk factors in the north-east of Spain, a population-based study. Ophthalmic Epidemiol 2010; 17: 251-265.

38. Knudsen LL, Lervang H-H, Lundbye-Christensen S, GorstRasmussen A. The North Jutland County Diabetic Retinopathy Study: population characteristics. Br J Ophthalmol 2006; 90: 1404-1409.

39. Kahloun R, Jelliti B, Zaouali S, Attia S, Ben Yahia S, Resnikoff $S$, et al. Prevalence and causes of visual impairment in diabetic patients in Tunisia, North Africa. Eye 2014; 28: 986-991. 
40. MacKy TA, Khater N, Al-Zamil MA, El Fishawy H, Soliman MM. Epidemiology of diabetic retinopathy in Egypt: A hospital-based study. Ophthalmic Res 2011; 45: 73-78.

41. Al Ghamdi AH, Rabiu M, Hajar S, Yorston D, Kuper H, Polack S. Rapid assessment of avoidable blindness and diabetic retinopathy in Taif, Saudi Arabia. Br J Ophthalmol 2012; 96: 1168-1172.

42. El-Bab MF, Shawki N, AL-Sisi A, Akhtar M. Retinopathy and risk factors in diabetic patients from Al-Madinah AlMunawarah in the Kingdom of Saudi Arabia. Clin Ophthalmol 2012; 6: 269-276.

43. Hajar S, Al Hazmi A, Wasli M, Mousa A, Rabiu M. Prevalence and causes of blindness and diabetic retinopathy in Southern Saudi Arabia. Saudi Med J 2015; 36: 449-455.

44. Khan A, Wiseberg J, Lateef ZA, Khan S. Prevalence and determinants of diabetic retinopathy in Al Hasa region of Saudi Arabia: primary health care centre based cross-sectional survey, 2007-2009. Middle East Afr J Ophthalmol 2010; 17: 257-263.

45. Alshaya AK, Alsayegh AK, Alshaya HK, Almutlaq BA, Alenazi NSG, Rasheedi HMA Al, et al. The common complications and comorbidities among Saudi diabetic patients in Northern Saudi Arabia. Open J Endocr Metab Dis 2017; 07: 151-161.

46. Pelzek C, Lim JI. Diabetic macular edema: Review and update. Ophthalmol Clin North Am 2002; 15: 555-563.

47. Misra GP, Imai H, Singh RJ, Lowe TL, Gardner TW. Diabetic retinopathy and diabetic macular edema. Retinal Pharmacotherapy 2010; 2010: 133-136.

48. Bandello F, Pognuz R, Polito A, Pirracchio A, Menchini F, Ambesi M. Diabetic macular edema: classification, medical and laser therapy. Semin Ophthalmol 2003; 18: 251-258.

49. Salz DA, Witkin AJ. Imaging in diabetic retinopathy. Middle East Afr J Ophthalmol 2015; 22: 145-150.

50. Sikorski BL, Malukiewicz G, Stafiej J, Lesiewska-Junk H, Raczynska D. The diagnostic function of OCT in diabetic maculopathy. Mediators Inflamm 2013; 2013: 434560.

51. Kim BY, Smith SD, Kaiser PK. Optical coherence tomographic patterns of diabetic macular edema. Am J Ophthalmol 2006; 142: 405-412.

52. Zur D, Iglicki $M$, Busch C, Invernizzi A, Mariussi M, Loewenstein A, et al. OCT biomarkers as functional outcome predictors in diabetic macular edema treated with dexamethasone implant. Ophthalmology 2018; 125: 267-275.

53. Baskin DE. Optical coherence tomography in diabetic macular edema. Curr Opin Ophthalmol 2010; 21: 172-177.

54. Bhende M, Shetty S, Parthasarathy M, Ramya S. Optical coherence tomography: A guide to interpretation of common macular diseases. Indian J Ophthalmol 2018; 66: 20-35.

55. Lee J, Moon BG, Cho AR, Yoon YH. Optical coherence tomography angiography of DME and its association with anti-VEGF treatment response. Ophthalmology 2016; 123: 2368-2375.

56. Hsieh YT, Alam MN, Le D, Hsiao CC, Yang CH, Chao DL, et al. OCT Angiography Biomarkers for predicting visual outcomes after ranibizumab treatment for diabetic macular edema. Ophthalmology Retina 2019; 3: 826-834.

57. Kwan CC, Fawzi AA. Imaging and biomarkers in diabetic macular edema and diabetic retinopathy. Curr Diab Rep 2019; 19: 95.

58. Kiire CA, Porta M, Chong V. Medical management for the prevention and treatment of diabetic macular edema. Surv Ophthalmol 2013 ; 58: 459-465.
59. Romero-Aroca P, Reyes-Torres J, Baget-Bernaldiz M, Blasco-Sune C. Laser treatment for diabetic macular edema in the 21st Century. Curr Diabetes Rev 2014; 10: 100-112.

60. Scholz P, Altay L, Fauser S. A review of subthreshold micropulse laser for treatment of macular disorders. Adv Ther 2017; 34: 1528-1555.

61. Early Treatment Diabetic Retinopathy Study Research Group. Treatment techniques and clinical guidelines for photocoagulation of diabetic macular edema. Ophthalmology 1987; 94: 761-774.

62. Diabetic Retinopathy Clinical Research Network (DRCR. net). Three-year follow-up of a randomized trial comparing focal/grid photocoagulation and intravitreal triamcinolone for diabetic macular edema. Arch Ophthalmol 2009; 127: 245.

63. Reddy SV, Husain D. Panretinal photocoagulation: a review of complications. Semin Ophthalmol 2018; 33: 83-88.

64. Dorin G. Evolution of retinal laser therapy: minimum intensity photocoagulation (MIP). Can the laser heal the retina without harming it? Semin Ophthalmol 2004; 19: 62-68.

65. Mitchell P, Bandello F, Schmidt-Erfurth U, Lang GE, Massin P, Schlingemann RO, et al. The RESTORE study: Ranibizumab monotherapy or combined with laser versus laser monotherapy for diabetic macular edema. Ophthalmology 2011; 118: 615-625.

66. Elman MJ, Aiello LP, Beck RW, Bressler NM, Bressler SB, Edwards AR, et al. Randomized trial evaluating ranibizumab plus prompt or deferred laser or triamcinolone plus prompt laser for diabetic macular edema. Ophthalmology 2010; 117 : 1064-1077.

67. Michaelides M, Kaines A, Hamilton RD, Fraser-Bell S, Rajendram R, Quhill F, et al. A prospective randomized trial of intravitreal bevacizumab or laser therapy in the management of diabetic macular edema (BOLT Study). 12-month data: Report 2. Ophthalmology 2010; 117: 1078-1086.

68. Browning DJ, Stewart MW, Lee C. Diabetic macular edema: Evidence-based management. Indian J Ophthalmol 2018; 66: 1736-1750.

69. Neubauer AS, Ulbig MW. Laser treatment in diabetic retinopathy. Ophthalmologica 2007; 221: 95-102.

70. Gross J. DRCR.net Prompt PRP vs ranibizumab+deferred PRP for PDR study (Protocol S). Presented at: American Academy of Ophthalmology. Nov. 13, 2015; Las Vegas.

71. Heier JS, Bressler NM, Avery RL, Bakri SJ, Boyer DS, Brown $\mathrm{DM}$, et al. Comparison of aflibercept, bevacizumab, and ranibizumab for treatment of diabetic macular edema. JAMA Ophthalmol 2016; 134: 95-99.

72. Su L, Ren X, Wei H, Zhao L, Zhang X, Liu J, et al. Intravitreal conbercept (KH902) for surgical treatment of severe proliferative diabetic retinopathy. Retina 2016; 36: 938-943.

73. Nguyen QD, Brown DM, Marcus DM, Boyer DS, Patel S, Feiner L, et al. Ranibizumab for diabetic macular edema. Ophthalmology 2012; 119: 789-801.

74. Schmidt-Erfurth U, Lang GE, Holz FG, Schlingemann RO, Lanzetta P, Massin P, et al. Three-year outcomes of individualized ranibizumab treatment in patients with diabetic macular edema. Ophthalmology 2014; 125: 1045-1053.

75. Das T, Aurora A, Chhablani J, Giridhar A, Kumar A, Raman $\mathrm{R}$, et al. Evidence-based review of diabetic macular edema management: Consensus statement on Indian treatment guidelines. Indian J Ophthalmol 2016; 64: 14-25. 
76. Saishin Y, Saishin Y, Takahashi K, Silva RLE, Hylton D, Rudge JS, et al. VEGF-TRAPR1R2 suppresses choroidal neovascularization and VEGF-induced breakdown of the blood-retinal barrier. J Cell Physiol 2003; 195: 241-248.

77. Korobelnik JF, Do DV, Schmidt-Erfurth U, Boyer DS, Holz FG, Heier JS, et al. Intravitreal aflibercept for diabetic macular edema. Ophthalmology 2014; 121: 2247-2254.

78. Chen YP, Wu AL, Chuang CC, Chen SN. Factors influencing clinical outcomes in patients with diabetic macular edema treated with intravitreal ranibizumab: comparison between responder and non-responder cases. Sci Rep 2019; 9: 10952.

79. Epstein D, Mirabelli P, Lövestam Adrian M. Treatment algorithm with dexamethasone intravitreal implant in patients with diabetic macular edema. Acta Ophthalmol 2020; 98 : e258-e529.

80. Elman MJ, Qin H, Aiello LP, Beck RW, Bressler NM, Ferris FL, et al. Intravitreal ranibizumab for diabetic macular edema with prompt versus deferred laser treatment: Three-year randomized trial results. Ophthalmology 2012; 119: 2312-2318.

81. Michaelides M, Kaines A, Hamilton RDR, Fraser-Bell S, Rajendram R, Quhill F, et al. A 2-Year Prospective Randomized Controlled Trial of Intravitreal Bevacizumab or Laser Therapy (BOLT 2) in the management of diabetic macular edema. Arch Ophthalmol 2012; 130: 972-979.

82. Schmidt-Erfurth U, Garcia-Arumi J, Bandello F, Berg K, Chakravarthy U, Gerendas BS, et al. Guidelines for the management of diabetic macular edema by the European Society of Retina Specialists (EURETINA). Ophthalmologica 2017; 237: 185-222.

83. Zhang Y, Ma J, Meng N, Li H, Qu Y. Comparison of intravitreal triamcinolone acetonide with intravitreal bevacizumab for treatment of diabetic macular edema: a meta-analysis. Curr Eye Res 2013; 38: 578-587.

84. Yolcu Ü, Sobaci G. The effect of combined treatment of bevacizumab and triamcinolone for diabetic macular edema refractory to previous intravitreal mono-injections. Int Ophthalmol 2015; 35: 73-79.

85. Durukan AH, Memisoglu S, Gundogan FC. Is multifocal ERG a reliable index of macular function after triamcinolone acetonide injection in diffuse diabetic macular edema? Eur J Ophthalmol 2009; 19: 1017-1027.

86. Elman MJ, Bressler NM, Qin H, Beck RW, Ferris FL, Friedman SM, et al. Expanded 2-year follow-up of ranibizumab plus prompt or deferred laser or triamcinolone plus prompt laser for diabetic macular edema. Ophthalmology 2011; 118: 609-614.

87. Gillies MC, Sutter FKP, Simpson JM, Larsson J, Ali H, Zhu M. Intravitreal triamcinolone for refractory diabetic macular edema. Two-year results of a double-masked, placebocontrolled, randomized clinical trial. Ophthalmology 2006; 113: 1533-1538.

88. Qi HP, Bi S, Wei SQ, Cui H, Zhao JB. Intravitreal versus subtenon triamcinolone acetonide injection for diabetic macular edema: a systematic review and meta-analysis. Curr Eye Res 2012; 37: 1136-1147.

89. Schwartz SG, Scott IU, Stewart MW, Flynn HW. Update on corticosteroids for diabetic macular edema. Clinical Ophthalmology 2016; 10: 1723-1730.

90. Cabrera M, Yeh S, Albini TA. Sustained-release corticosteroid options. J Ophthalmol 2014; 2014: 1-5.

91. Bahrami B, Hong T, Zhu M, Schlub TE, Chang A. Switching therapy from bevacizumab to aflibercept for the management of persistent diabetic macular edema. Graefe's Arch Clin Exp Ophthalmol 2017; 255: 1133-1140.
92. Kaiho T, Oshitari T, Tatsumi T, Takatsuna Y, Arai M, Shimizu $\mathrm{N}$, et al. Efficacy of one-year treatment with aflibercept for diabetic macular edema with practical protocol. Biomed Res Int 2017; 2017: 1-6.

93. Aksoy S, Yilmaz G, Akkoyun I, Yazici AC. Comparison of intravitreal bevacizumab and triamcinolone acetonide theraphies for diffuse diabetic macular edema. Int J Ophthalmol 2015; 8: 550-555.

94. Fong DS, Luong TQ, Contreras R, Jimenez JJ, Custis PH, Patel V, et al. Treatment patterns and 2-year vision outcomes with bevacizumab in diabetic macular edema an analysis from a large U.S. Integrated health care system. Retina 2018; 38: 1830-1838.

95. Güler E, Totan Y, Betül Güragaç F. Intravitreal bevacizumab and dexamethasone implant for treatment of chronic diabetic macular edema. Cutan Ocul Toxicol 2017; 36: 180-184.

96. Koç I, Kadaylfçllar S, Eldem B. Real-world results of intravitreal ranibizumab, bevacizumab, or triamcinolone for diabetic macular edema. Ophthalmologica 2018; 239: 85-93.

97. Riazi-Esfahani M, Riazi-Esfahani H, Ahmadraji A, Karkhaneh R, Mahmoudi A, Roohipoor R, et al. Intravitreal bevacizumab alone or combined with $1 \mathrm{mg}$ triamcinolone in diabetic macular edema: a randomized clinical trial. Int Ophthalmol 2018; 38: 585-598.

98. Cheema HR, Al Habash A, Al-Askar E. Improvement of visual acuity based on optical coherence tomography patterns following intravitreal bevacizumab treatment in patients with diabetic macular edema. Int J Ophthalmol 2014; 7: 251-255.

99. Ciulla TA, Hussain RM, Ciulla LM, Sink B, Harris A. Ranibizumab for diabetic macular edema refractory to multiple prior treatments. Retina 2016; 36: 1292-1297.

100. Egan C, Zhu H, Lee A, Sim D, Mitry D, Bailey C, et al. The United Kingdom Diabetic retinopathy electronic medical record users group, report 1: Baseline characteristics and visual acuity outcomes in eyes treated with intravitreal injections of ranibizumab for diabetic macular oedema. $\mathrm{Br} \mathrm{J}$ Ophthalmol 2017; 101: 75-80.

101. Fassbender Adeniran JM, Jusufbegovic D, Schaal S. Common and rare ocular side-effects of the dexamethasone implant. Ocul Immunol Inflamm 2017; 25: 834-840.

102. Boyer DS, Yoon YH, Belfort R, Bandello F, Maturi RK, Augustin AJ, et al. Three-year, randomized, sham-controlled trial of dexamethasone intravitreal implant in patients with diabetic macular edema. Ophthalmology 2014; 121: 1904-1914.

103. Callanan DG, Gupta S, Boyer DS, Ciulla TA, Singer MA, Kuppermann BD, et al. Dexamethasone intravitreal implant in combination with laser photocoagulation for the treatment of diffuse diabetic macular edema. Ophthalmology 2013; 120: 1843-1851.

104. Cebeci Z, Kir N. Role of implants in the treatment of diabetic macular edema: Focus on the dexamethasone intravitreal implant. Diabetes Metab Syndr Obes 2015; 8: 555-566.

105. Murakami T, Yoshimura N. Structural changes in individual retinal layers in diabetic macular edema. J Diabetes Res 2013; 2013: 920713.

106. Dugel PU, Campbell JH, Kiss S, Loewenstein A, Shih V, $\mathrm{Xu} \mathrm{X}$, et al. Association between early anatomic response to anti-vascular endothelial growth factor therapy and long-term outcome in diabetic macular edema: an independent analysis of protocol I study data. Retina 2019; 39: 88-97. 
107. Gonzalez VH, Campbell J, Holekamp NM, Kiss S, Loewenstein A, Augustin AJ, et al. Early and long-term responses to anti-vascular endothelial growth factor therapy in diabetic macular edema: analysis of protocol I data. Am J Ophthalmol 2016; 172: 72-79.

108. Cicinelli MV, Cavalleri M, Querques L, Rabiolo A, Bandello F, Querques G. Early response to ranibizumab predictive of functional outcome after dexamethasone for unresponsive diabetic macular oedema. Br J Ophthalmol 2017; 101: 1689-1693.

109. Busch C, Zur D, Fraser-Bell S, Laíns I, Santos AR, Lupidi M, et al. Shall we stay, or shall we switch? Continued anti-VEGF therapy versus early switch to dexamethasone implant in refractory diabetic macular edema. Acta Diabetol 2018; 55: 789-796.

110. Chatziralli I, Theodossiadis P, Parikakis E, Dimitriou E, Xirou T, Theodossiadis G, et al. Dexamethasone intravitreal implant in diabetic macular edema: real-life data from a prospective study and predictive factors for visual outcome. Diabetes Ther 2017; 8: 1393-1404.

111. Iglicki M, Busch C, Zur D, Okada M, Mariussi M, Chhablani JK, et al. Dexamethasone implant for diabetic macular edema in naive compared with refractory eyes: The international retina group real-life 24-month multicenter study: The irgrel-dex study. Retina 2019; 39: 44-51.

112. Guigou S, Pommier S, Meyer F, Hajjar C, Merite PY, Parrat E, et al. Efficacy and safety of intravitreal dexamethasone implant in patients with diabetic macular edema. Ophthalmologica 2015; 233: 169-175.

113. Pareja-Ríos A, Ruiz-De la Fuente-Rodríguez P, BonaqueGonzález S, López-Gálvez M, Lozano-López V, Romero-Aroca P. Intravitreal dexamethasone implants for diabetic macular edema. Int J Ophthalmo 2018; 11: 77-82.

114. Bellocq D, Akesbi J, Matonti F, Vartin C, Despreaux R, Comet $\mathrm{A}$, et al. The pattern of recurrence in diabetic macular edema treated by dexamethasone implant: The PREDIAMEX study. Ophthalmol Retin 2018; 2: 567-573.

115. Malcles A, Dot C, Voirin N, Agard E, Vie AL, Bellocq D, et al. Real-life study in diabetic macular edema treated with dexamethasone implant: The reldex study. Retina 2017; 37: 753-760.

116. Scaramuzzi M, Querques G, Spina C La, Lattanzio R, Bandello F. Repeated intravitreal dexamethasone implant (ozurdex) for diabetic macular EDEMA. Retina 2015; 35: 1216-1222.

117. Ozsaygili C, Duru N. Comparison of intravitreal dexamethasone implant and aflibercept in patients with treatment-naive diabetic macular edema with serous retinal detachment. Retina 2020; 40: 1044-1052.

118. Augsburger M, Sarra GM, Imesch P. Treat and extend versus pro re nata regimens of ranibizumab and aflibercept in neovascular age-related macular degeneration: a comparative study. Graefe's Arch Clin Exp Ophthalmol 2019; 257: 1889-1895.
119. Rosenthal JM, Johnson MW. Management of retinal diseases in pregnant patients. J Ophthalmic Vis Res 2018; 13: 62-65.

120. Baker CW, Glassman AR, Beaulieu WT, Antoszyk AN, Browning DJ, Chalam K V, et al. Effect of initial management with aflibercept vs laser photocoagulation vs observation on vision loss among patients with diabetic macular edema involving the center of the macula and good visual acuity: a randomized clinical trial. JAMA 2019; 321: 1880-1894.

121. Regillo CD, Callanan DG, Do D V., Fine HF, Holekamp NM, Kuppermann BD, et al. Use of corticosteroids in the treatment of patients with diabetic macular edema who have a suboptimal response to anti-VEGF: recommendations of an expert panel. Ophthalmic Surg Lasers Imaging Retina 2017; 48: 291-301.

122. García Layana A, Adán A, Ascaso FJ, Cabrera F, Donate J, Escobar Barranco JJ, et al. Use of intravitreal dexamethasone implants in the treatment of diabetic macular edema: Expert recommendations using a Delphi approach. Eur J Ophthalmol 2020; 30: 1042-1052.

123. Giovannini A, Parravano M, Ricci F, Bandello F. Management of diabetic macular edema with intravitreal dexamethasone implants: expert recommendations using a Delphi-based approach. Eur J Ophthalmol 2019; 29: 82-91.

124. Kodjikian L, Bellocq D, Bandello F, Loewenstein A, Chakravarthy U, Koh A, et al. First-line treatment algorithm and guidelines in center-involving diabetic macular edema. Eur J Ophthalmol 2019; 29: 573-584.

125. Bandello F, Cicinelli M, Parodi M. Anti-VEGF molecules for the management of diabetic macular edema. Curr Pharm Des 2015; 210: 4731-4737.

126. Vujosevic S, Torresin T, Berton M, Bini S, Convento E, Midena E. Diabetic macular edema with and without subfoveal neuroretinal detachment: two different morphologic and functional entities. Am J Ophthalmol 2017; 181: 149-155.

127. Elman MJ, Sloan MD, Starr JA, Butcher TM, Singletary P $\mathrm{V}$, Gore N, et al. Observational study of subclinical diabetic macular edema. Eye (Lond) 2012; 26: 833-840.

128. Boyle J, Vukicevic M, Koklanis K, Itsiopoulos C, Rees G. Experiences of patients undergoing repeated intravitreal antivascular endothelial growth factor injections for neovascular age-related macular degeneration. Psychol Heal Med 2018; 23: 127-140.

129. Ramu J, Chatziralli I, Yang Y, Menon G, Bailey C, Eckstein $M$, et al. Health-related quality of life, visual function and treatment satisfaction following intravitreal dexamethasone implant for diabetic macular edema. Patient Prefer Adherence 2017; 11: 579-586.

130. Patel AJ, Downes K, Davis A, Das A. Are proliferative diabetic retinopathy and diabetic macular edema two different disease processes? A retrospective cross-sectional. Investig Ophthalmol Vis Sci 2012; 53: 377. 